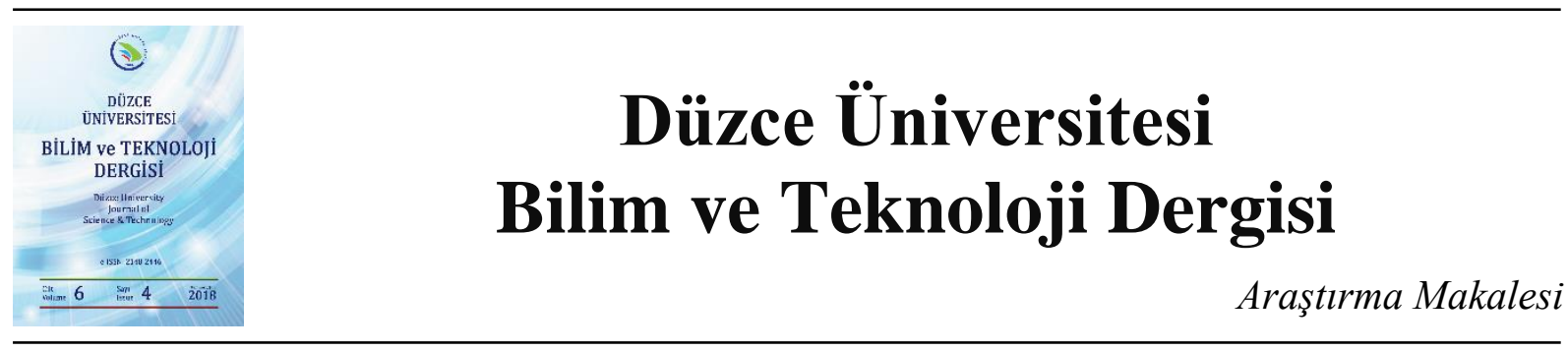

\section{Düzce Yöresi Sapsız Meşe Meşcerelerinde Aralamaların Su Sürgünü Oluşumuna Beş Yıllık Etkileri}

\author{
Ali Kemal ÖZBAYRAM ${ }^{a, *}$ \\ ${ }^{a}$ Orman Mühendisliği Bölümü, Orman Fakültesi, Düzce Üniversitesi, Düzce, TÜRKIYE \\ *Sorumlu yazarin e-posta adresi: alikemalozbayram@duzce.edu.tr
}

\begin{abstract}
ÖZET
Aralama, ormanların yönetimi ve işletilmesinde en uzun süre kullanılan silvikültürel müdahale yöntemidir. Aralamalardaki genel amaç kaliteli ve kalın çaplı gövdeye sahip bireylerin üretilmesidir. Ancak, meşe gibi birçok yapraklı ağaç türlerinde aralamalar nedeniyle gövde üzerinde su sürgünü oluşabilmekte buda gövde kalitesini düşürebilmektedir. Bu çalışmanın amacı Düzce yöresindeki 22 yaşındaki saf sapsız meşe (Quercus petraea Liebl.) meşceresinde uygulanan farklı aralama şiddetlerinin su sürgünü oluşumuna beş y1llık etkisini araştırmaktır. Aralama öncesi meşceredeki birey sayısı 2665 adet ha $^{-1}$, ortalama göğüs yüksekliği çap1 $7.7 \mathrm{~cm}$ ve meşcere göğüs yüzeyi (GY) $14.0 \mathrm{~m}^{2}$ ha $^{-1}$ dır. Aralama ile GY’nin $\% 0$ (kontrol), \%18 (mutedil) ve \%32 (kuvvetli) çıkartılmıştır. Aralamadan beş yıl sonra deneme sahasındaki dokuz farklı parseldeki farklı sosyal ve çap sınıflarını temsil eden 30'ar ağaçta su sürgünü sayımları yapılmıştır. Varyans analizi sonuçlarına göre; aralamadan beş yıl sonra tüm işlemlerde su sürgünü sayısını benzer bulunmuştur. Ancak, ağaçlarda çap sınıfı inceldikçe ve galip tabakadan mağlup tabakaya doğru gittikçe su sürgünü miktarı artmıştır. Sonuç olarak istikbal ağacı özelliği taşıyan galip tabakadaki en kalın çaplı ağaçlarda \%32’ye varan kuvvetli aralamalar, su sürgünü oluşturma riski düşük olduğu için, önerilebilir.
\end{abstract}

Anahtar Kelimeler: Aralama şiddeti, çap sinıflarl, Quercus petraea, su sürgünü

\section{Five-Year Effects of Thinning on Epicormic Branching in a Sessile Oak Stand in Düzce}

\begin{abstract}
Thinning is the longstanding silvicultural intervention method most frequently used in the management and operation of forests. The overall aim of thinning is to produce individuals with high-quality, thick-diameter trunks. However, in many broadleaved tree species such as oak, thinning may generate epicormic branching on the stem and this can reduce the quality of the trunk. The aim of this study was to investigate the five-year effect of different thinning intensities on epicormic branching formation. The treatments were applied in a 22 -year-old pure sessile oak (Quercus petraea Liebl.) stand in the Düzce region. Before thinning, the number of trees was $2665 \mathrm{ha}^{-1}$, with a mean diameter of $7.7 \mathrm{~cm}$ and stand basal area of $14 \mathrm{~m}^{2} \mathrm{ha}^{-1}$. Selective thinning was applied by removing $0 \%$ (control), $18 \%$ (moderate) and 32\% (heavy) of the initial basal area. Five years after thinning,
\end{abstract}


epicormic branching counts were made of 30 trees representing different social and diameter classes in the nine parcels. According to the variance analysis results, five years after thinning, the amount of epicormic branching was similar in all thinning treatments. However, the epicormic branching increased as the diameter class became smaller and from the dominant trees to the suppressed trees. As a result, heavy thinning of up to $32 \%$ may be recommended in sessile oak stands, especially for crop trees, since the risk of epicormic branching is low.

\section{GiRIS}

$\mathrm{G}$ eçen süreç içinde, ülkemiz kaliteli yapraklı ormanlarının önemli bir bölümünü yitirmiş olup, bu ormanlar iç piyasa gereksinimlerini karşılamada yetersiz kalmaktadır. Ülkemiz endüstriyel yuvarlak ve yakacak odun ihracat miktarı, yıllık odun ithalat miktarları dikkate alındığında önemsiz denilecek kadar çok düşük miktardadır. Odun ithalatı miktarı 1995-2009 yılları arasındaki verilere göre ortalama 1,3 milyon $\mathrm{m}^{3} \mathrm{y}^{-1}{ }^{-1}$ civarında olup, yıllık ortalama 144 milyon dolar harcanmaktadır [1]. $\mathrm{Bu}$ ithalatın yaklaşık \% 80'ini oluşturan endüstriyel odunun tamamı tomruktan oluşmaktadır. Yapraklı odun ithalatının neredeyse tamamını kaliteli ve kalın çaplı tomruk oluşturmaktadır. Diğer taraftan, odun hammaddesi ihracatında önemli yere sahip ülkelerin (Örn. Rusya) ihracat vergilerini artırması nedeniyle her ülkenin kendi odun ihtiyacını giderek artan oranda kendi öz kaynaklarından karşılamak zorunda kalacağı bildirilmektedir [2].

Ülkemizin artan odun hammaddesi ihtiyacının karşılanması mevcut ormanlarımızın teknik müdahalelerle kalitesini ve verimini yükseltmekle mümkün olacaktır. Meşcere yetiştirmede en önemli bakım tedbirlerinden biri aralama olup türe ve yetişme ortamı özelliklerine göre zamanında ve düzenli olarak yapılacak bakımlar kaliteli ve kalın çaplı odun ürünü üretimi için kullanılabilecek en önemli silvikültürel araçtır [3, 4] . Nitekim Saatçioğlu [5] en önemli bakım tedbirinin aralama olduğunu ifade etmektedir. Spiecker [6] aşırı gövde sıklığı ve gövde ayrılmasından kaynaklanan artım kayıplarını en aza indirmek ve ormanların canlılığını ve çeşitliliği korumak için aralama müdahalelerinin zorunlu olduğunu bildirmektedir. Diğer yandan; yetişme ortamı, ağaç türü ve meşcere kuruluş özelliklerine bağlı olarak, farklı şiddetlerde uygulanacak aralamaların, meşcere kuruluşu ve gelişimi yanında ağaçların biçimi ve gelişimi ile meşcere sağlı̆̆ı, toprak özellikleri ve meşcerenin gelecekteki gençleştirme koşulları üzerine büyük ölçüde etkili olduğu ifade edilmektedir [7].

Üretilecek ürünün miktarından çok, kalitesi ön planda ise aralama müdahaleleri çok daha büyük önem taşımaktadır. Aralamanın meşcere genel verimi üzerine etkisi konusunda henüz bir fikir birliği yoktur. Ancak aralamanın meşcere kalitesini ve buna bağlı olarak meşcerenin değerini yükselttiği hususunda ortak görüş vardır [8]. Ancak özellikle yapraklı türlerde silvikültürel müdahaleler sonucunda ticari öneme sahip gövde üzerinde oluşan su sürgünleri odunun değerini düşürebilmektedir. Kuvvetli aralama ile gövde üzerinde su sürgünü oluşmasına neden olabilmektedir [9]. Aralamaya bağlı su sürgünü oluşumu, ağaç gövdelerinin hızlı bir şekilde güneş ışığına maruz kaldığı için meydana geldiği sanılıyorken, araştırmalar neticesinde su sürgünü oluşumu ağacın sosyal konumu ve yaşama gücüyle yakın ilişkili olduğu anlaşılmıştır [10, 11]. Meadows [12]'e göre yapraklı ağaçlarda su sürgünü oluşumu ağaç türü, stres ve 1şık faktörleriyle yakın ilişkilidir. Aralama ile meşcere içerisine giren 1şık miktarı artmakta, buna bağlı kalan ağaçlar ani olarak daha fazla ışık alması sonucu su sürgünü 
oluşumu teşvik edebilmektedir. Özellikle meşe türlerinde su sürgünü oluşması diğer yapraklılara nazaran çok daha yüksektir [13].

Meşe cinsinin ülkemizde doğal olarak 18 türü, 7 alt türü ve 2 varyetesi yayıllış göstermektedir $[14,15]$. Türkiye'de yayılış gösteren orman ağaçları arasında meşeler kızılçam türünden sonra en geniş yayılış alanına sahiptir. Ancak tür bazında ne kadar alanda yayılış yaptığı konusunda yeterli bilgi yoktur. Türkiye orman varlığının \% 23.7'ini (5.15 milyon hektar) meşe türleri oluşturmaktadır. Bu meşelerden \% 41'i normal kapalılıkta iken \% 59'u ise bozuk vasıftadır [16]. Meşe türlerinden yapacak odun verimi yüksek önemli meşe taksonları $Q$. robur, $Q$. petraea, $Q$. hartwissiana, Q.frainetto, $Q$. vulcanica' dır [15, 17]. Özellikle sapsız meşe Türkiye'de geniş yayılış alanına sahiptir. Aralama şiddetinin sapsız meşede ticari öneme sahip gövde kısmında su sürgünü oluşumuna etkisi hususunda yeterli bilgi bulunmamaktadır. Bu çalışmanın amacı aralama şiddeti, çap sınıfları ve sosyal sınıfın sapsız meşe bireylerinde su sürgünü oluşumuna etkisinin 5 yıllık sonuçlarını değerlendirmektir.

\section{MATERYAL VE YÖNTEM}

\section{A. DENEME SAHASININ TANITIMI}

Deneme sahası Düzce Orman İşletme Müdürlüğü, Konuralp Orman İşletme Şefliği sınırları içerisinde $\left(40^{\circ} 54.52^{\prime} \mathrm{K}, 31^{\circ} 10.69^{\prime} \mathrm{D}\right)$ yer almaktadır. Saha $305 \mathrm{~m}$ rakımda, \% 26 eğimde ve güney bakıda bulunmaktadır. Amenajman planında saha Mab3 tipinde ve III. Bonitet olarak gösterilmektedir. Deneme sahasında aralama öncesi ağaç sayısı hektarda 2665 adet, ortalama yaşı 22, ortalama göğüs yüksekliği çapı $7.72 \mathrm{~cm}$, ortalama ağaç boyu $7.0 \mathrm{~m}$, gögüs yüzyi (GY) ise $14.0 \mathrm{~m}^{2} \mathrm{ha}^{-1} \mathrm{~d}$ dr. Sapsız meşe altında Akçakesme (Phillyrea latifolia), Funda (Erica arborea), Tavşan Memesi (Ruscus aculeatus), Alıç (Crataegus monogyna) gibi diri örtü türleri nadiren yayılış göstermektedir. Sahanın toprağı $120 \mathrm{~cm}$ 'den derin, balçık toprak türüne sahiptir. Toprağın pH'sı 4.1-5.6 arasında değişirken, tuzluluk $45 \mu \mathrm{Sm}^{-1}$ 'dır.

Deneme sahasının iklim verileri Düzce meteoroloji verilerinin (146m) enterpole edilmesiyle bulunmuştur [18]. Deneme sahasının yıllık toplam yağışı $911.4 \mathrm{~mm}$, ortalama sıcaklık $12.5{ }^{\circ} \mathrm{C}$ dir. Sahada vejetasyon dönemi Nisan- Ekim ayları arasında gerçekleşmekte olup bu dönemde toplam 452 mm yağgş düşmektedir.

\section{B. YÖNTEM}

Saf sapsız meşe mesceresinde 2012 yılında $1600 \mathrm{~m}^{2}(40 \mathrm{~m}$ x $40 \mathrm{~m})$ büyüklüğündeki 9 farklı deneme parselleri belirlenmiştir. Parsel kenarlarında 15 m'lik şeritler izolasyon amaçlı bırakılarak parsellerin orta kısmındaki $625 \mathrm{~m}^{2}(25 \mathrm{~m} \times 25 \mathrm{~m})$ büyüklüğündeki alan ölçüm ve değerlendirme amacı ile kullanılmıştır. Deneme alanlarında 2012 yılında iki farklı aralama şiddeti uygulanmış ve müdahale şiddetinin belirlenmesinde GY esas alınmıştır. Kontrol parsellerinde müdahale uygulanmazken, mutedil parsellerde GY'nin \% 18'i kuvvetli parsellerde ise GY'nin \% 32'si meşcereden çıkartılmıştır. Aralama uygulanan parsellerde alt tabakadaki bireylere dokunulmamış, ara ve üst tabakadaki bireylere müdahale edilerek yüksek aralama uygulanmıştır. Aralamadan beş yıl sonra (2017 yılında) her bir parselde değişik gövde sınıflarını temsil eden 30 ağaçta su sürgünü sayımı yapılarak toplamda 270 adet ağaç üzerinde sayım yapılmıştır. Su sürgünü sayımları ağaç üzerinde ticari öneme sahip 0.0-6.0 m'lik gövde kısmında gerçekleştirilmiştir. Su sürgünü çapı ve boyu ayrımı yapılmamıştır. Su sürgünü 
sayımı yapılan gövdelerin çap sınıfları ayrımları yapılarak, çap basamaklarına göre su sürgünü sayımları yapılmıştır.

\section{ISTATISTIKI ANALIZ}

Aralama şiddeti ( 3 seviye) ve sosyal sınıfi (3 seviye) faktörleri ile bu faktörlerin etkileşimlerinin, ayrıca aralama şiddeti ve çap sınıfları faktörleri ile faktör etkileşimlerinin su sürgünü sayısına etkisi belirlemek için ölçülen verilere iki-yönlü varyans (ANOVA) analizi uygulanmıştır $(p<0.05)$. Analiz öncesi verilere gerekli dönüşümler yapılmıştır. Ortalamaların karşılaştırılmasında duncan testi kullanıldı. İstatistik analizler IBM-SPSS Ver.22 istatistik paket programında gerçekleştirilmiştir.

\section{BULGULAR VE TARTIȘMA}

Aralama şiddeti ve sosyal sınıf etkileşiminin meşe gövdelerinde beş yıllık su sürgünü sayısına etkisi önemsizdir. Ayrıca, aralama şiddeti ve çap sınıfları etkileşiminin de su sürgünü sayısına etkisi istatistiki olarak anlamsızdır ( $\mathrm{p}>0.05$ ). Bunun yanında aralama şiddeti faktörünün su sürgünü sayısına etkisi de istatistiki olarak anlamlı bulunmamıştır. Aralamadan beş yıl sonra sapsız meşelerde ortalama 6.3 adet su sürgünü sayılmıştır (Şekil 1). Aralamanın amacı, meşcerede kalan ağaçların özellikle galip tabakada bulunan istikbal ağaçlarının tepe gelişimi ve buna bağlı çap artımını artırmaktır. İstikbal ağaçlarının ticari olarak önemli gövde kısımlarını oluşturan kısımlarında kontrole göre önemsenecek kadar su sürgünü oluşumu meydana gelmemiştir. Dünya literatüründe aralamanın su sürgününe etkisine ilişkin değişik sonuçlar bulunmaktadır. Meşe gibi bazı yapraklı türlerin aralama sonucunda güneş alan gövde kısımlarında su sürgünü verme eğilimi olabilmektedir. Örneğin, sapsız meşede [19, 20], saplı meşede [19], Q. mongolica [21] \% 50 ye varan aralanmış parsellerde kontrole göre daha fazla su sürgünü oluşturduğu bildirilmektedir. Dimov ve diğ. [9] Q. pagoda türünde uygulanan aralamanın beş yıllık sonuçlarına göre tüm müdahale şiddetlerinde su sürgünü sayısının arttığını belirtmişlerdir. Buna zıt olarak, Meadows and Goelz [22] atmış yaşlarındaki Quercus falcata ve Liquidambar stryradiflua hakim olduğu ormanlarda \% 50 ye varan aralama müdahalelerinin dört yıllık sonuçlarına göre, aralama meşede su sürgününü sayısını çok az etkilerken, sığla da önemli oranda artırdığını belirtmişlerdir. Wignall ve diğ. [23] aralamanın saplı meşede su sürgünü sayısı üzerine etki etmediğini bildirmektedir. Ayrıca çalışmamıza benzer şekilde bazı yapraklı türlerde de aralamanın su sürgünü miktarını artırmadığını belirten çalışmalar vardır [24, 25]. Bu çalışmada bulunan sonuçlar meşede yapılan diğer çalışmalarla genel olarak uyuşmamaktadır. Bunun nedeni meşelerde yapılan diğer çalışmalarda aralamaların \% 50 ve daha yüksek şiddetlere çıkarken, bu çalışmada en yüksek \% 32 düzeyinde olmasına bağlı olarak; meşcere içerisine fazla 1şık girmemiş ve su sürgünü oluşumunu daha az tetiklemiş olabilir. Ayrıca bu çalışmadaki sapsız meşe meşcerelerin daha genç olması da aralamaya bağl1 su sürgünü oluşumuna daha az etki etmesine neden olmuş olabilir. 


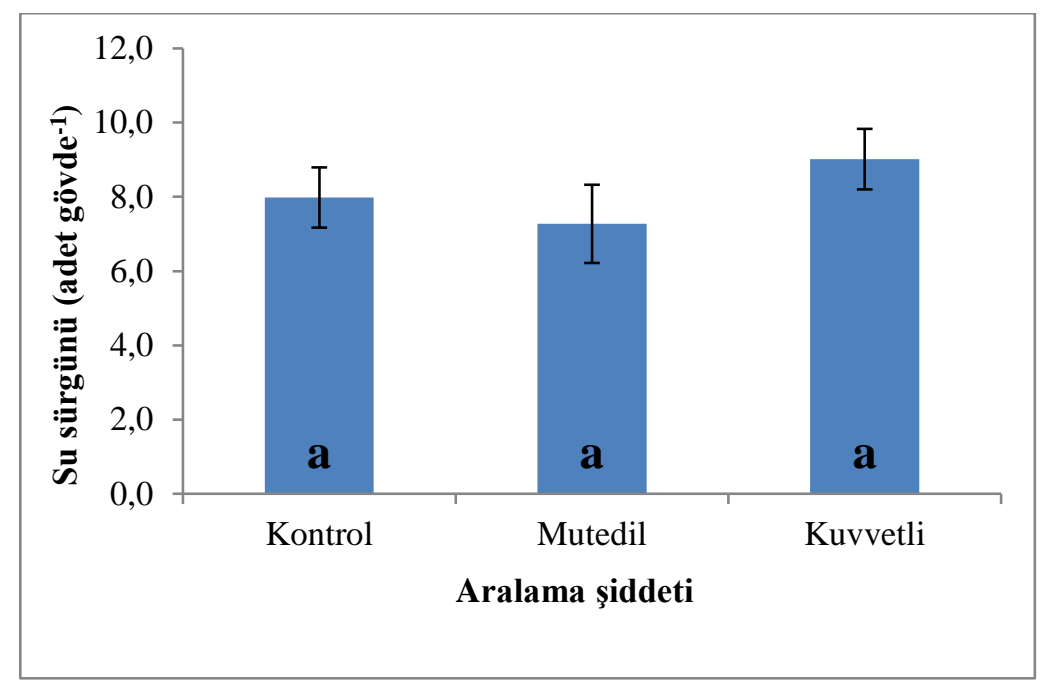

* Grafikte aynı harfle gösterilen değerler istatistiki olarak benzerdir $(\mathrm{P}>0.05)$.

Şekil 1. Sapsız meşe meşceresinde aralama şiddetinin su sürgünü sayısına etkisi

Ağaçlarda sosyal sınıfın ve çap sınıfının su sürgünü sayısına etkisi önemli bulunmuştur $(\mathrm{P}<0.05)$. Sosyal sınıfa göre su sürgünü dağılımı tablo 1'de verilmiştir.

Tablo 1. Aralamadan beş yıl sonra sapsız meşe meşceresinde farklı sosyal sınıftaki ağaçlarda su sürgünü sayısı

\begin{tabular}{lcccc}
\hline \multicolumn{1}{c}{ Sosyal Sınıf } & Ortalama & $\begin{array}{c}\text { Standart } \\
\text { hata }\end{array}$ & Minimum & Maximum \\
\hline Galip gövdeler & $5.8 \mathrm{a}^{*}$ & 0.7 & 1.0 & 21.0 \\
Ara tabakadaki gövdeler & $7.6 \mathrm{~b}$ & 0.7 & 1.0 & 20.0 \\
Mağlup gövdeler & $10.0 \mathrm{c}$ & 1.2 & 1.0 & 27.0 \\
\hline
\end{tabular}

* Sütunda aynı harfle gösterilen değerler istatistiki olarak benzerdir $(\mathrm{P}>0.05)$.

En yüksek su sürgünü alt tabakada, sonra ara tabakada ve en düşük galip tabakadaki bireylerde sayılmıştır. Mağlup tabakadaki bireylerde, galip tabakadaki bireylere göre \% 71, ara tabakadaki bireylere göre ise \%31 daha fazla su sürgünü bulunmaktadır (Tablo 1). Çap sınıflarının su sürgünü miktarına bakıldığında; çap sınıfı arttıkça gövde üzerindeki su sürgünü sayısı azalmaktadır (Tablo 2).

Tablo 2. Aralamadan beş yıl sonra sapsız meşede çap sınıflarına göre su sürgünü değişimi

\begin{tabular}{ccccc}
\hline Çap Sınıfi (cm) & Ortalama & $\begin{array}{c}\text { Standart } \\
\text { hata }\end{array}$ & Minimum & Maximum \\
\hline $0.0-3.9$ & $11.8 \mathrm{c}^{*}$ & 3.7 & 1.0 & 22.0 \\
$4.0-7.9$ & $9.7 \mathrm{ab}$ & 0.8 & 1.0 & 25.0 \\
$8.0-11.9$ & $6.8 \mathrm{ab}$ & 0.7 & 1.0 & 27.0 \\
$12.0-15.9$ & $8.5 \mathrm{ab}$ & 1.9 & 1.0 & 27.0 \\
$16.0-20.0$ & $2.5 \mathrm{a}$ & 1.5 & 0.0 & 4.0 \\
\hline
\end{tabular}

${ }^{*}$ Sütunda aynı harfle gösterilen değerler istatistiki olarak benzerdir $(\mathrm{P}>0.05)$.

En kalın çaplı $(>16 \mathrm{~cm})$ ağaçlara nazaran ince çaplı ağaçlarda yaklaşık 5 kata kadar daha fazla su sürgünü mevcuttur. Baskı derecesinin artması ve çap sınıfının azalmasına bağlı olarak su sürgünü 
sayısında artış olmaktadır. Meşe türlerinde ve yapraklı diğer türlerde yapılan birçok çalışmada benzer sonuçlar bulunmuştur. Dimov ve diğ. [9] galip tabakadaki meşe ağaçlarının alt tabakadaki ağaçlara nazaran daha az su sürgünü oluşturduğunu belirtmişlerdir. Ara ve alt tabakadaki $Q$. falcata [26] ve $Q$. nigra [22] ağaçlarında galip tabakaya nazaran daha fazla su sürgünü olduğu gözlemlenmiştir. Clatterbuck [27] meşeler baskı altına girdiklerinde ve strese tabi tutulduklarında su sürgünü verme eğilimi olduğunu belirtmektedir. Çiçek ve diğ. [25] dar yapraklı dişbudak plantasyonundaki galip tabakadaki kalın çaplı ağaçların su sürgünü sayısı ortalama 1 den az olup, ara tabakada ve daha ince çap sınıfından daha az su sürgünü oluşturduğunu bildirmektedir.

Galip tabakada yer alan en kalın çap sınıfındaki ağaçlarda oldukça düşük sayıda su sürgünü oluştuğu ( maksimum 4 adet) ve oluşan su sürgünlerin genelde gövdenin üst kısmındaki dalların başlangıç kısmına yakın olduğu gözlemlemiştir. Bu durum, gövdenin üst kısmındaki su sürgünlerinin daha aktif olduğunu, aralama gibi dış müdahalelerde buralarda ilk su sürgünlerinin oluşabileceği şeklinde açıklanmaktadır [28]. İstikbal ağaçları olarak nitelendirilen bu ağaçlarda az sayıda su sürgünü bulunması ve bunlarında ticari öneme sahip gövdenin (4-6 m) üst kısmında yer alması gövde kalitesini bozacak önemde olmadığını ortaya koymaktadır.

\section{SONUÇ VE ÖNERILER}

Aralama şiddetine bağlı olarak su sürgünü oluşumunda önemli bir değişkenlik olmamıştır. Su sürgünü oluşumu ağaç çapı inceldikçe ve galip tabakadan mağlup tabakaya doğru gidildikçe artmıştır. Yani ağaçlar üzerindeki baskı derecesi arttıkça ağaçların su sürgünü verme eğilimi artmıştır. Buda sapsız meşede su sürgünü oluşumu ile yaşama gücü arasında ilişki olduğunu gösterebilir. Bu bağlamda sapsız meşede \% 32'ye varan kuvvetli aralamalar su sürgünü oluşumunda önemli sorun teşkil etmeyebilir. Su sürgünü riskini azaltmak için türde yüksek aralamalar uygulanmalı ve mutlak suretle alt tabakaya dokunulmamalıdır. Ayrıca sapsız meşe türünde tek seferde çok kuvvetli (>35) aralamalar yerine daha 1lımlı ve sık yüksek aralamalar önerilebilir.

TEŞEKKÜR: Arazi çalışmasının gerçekleştirilmesinde yardımlarını gördüğüm Orman Mühendisliği Bölümü Lisans öğrencileri Elif Karakurt, Burcu Aydemir ve Ömer Er ile Lisansüstü öğrencileri Yusuf Ercan ve Yasin Özkuru’ya teşekkür ederim.

\section{KAYNAKLAR}

[1] B. Kayacan, O. Kara, M. Ş. Ucal, A. Öztürk, R. Balı, S. Koçer and E. Kaplan, "An econometric analysis of imported timber demand in Turkey," Journal of Food, Agriculture \& Environment, vol. 11, pp. 791-794, 2013.

[2] I. Eastin and J. Turner, "The impact of the Russian log export tariff on the global market for logs and lumber," Center for the International Trade in Forest Products (CINTRAFOR Newsletter), University of Washington, Seattle, USA, Winter 1, 2009. 
[3] E. Çiçek, F. Yılmaz, M. Yılmaz, ve B. Çetin, "Aralamanın Dar Yapraklı Dişbudak (Fraxinus angustifolia Vahl.) plantasyonlarında çap ve göğüs yüzeyi gelişimine etkisi: Bir yıllık sonuçlar," $D \ddot{U}$ Ormancllik Dergisi, c.3, s.1, ss. 90-99, 2007.

[4] E. Çiçek, F. Yılmaz, A. K. Özbayram, M. Efe, M. Yılmaz and A. Usta, "Effects of thinning intensity on the growth of narrow-leaved ash (Fraxinus angustifolia subsp. oxycarpa) plantations," Turkish Journal of Agriculture and Forestry, vol. 37, pp. 97-104, 2013.

[5] F. Saatçioğlu, Orman Bakımı: Meşcere yetiştirmesine ait tedbirler, 4. bask1, İstanbul, Türkiye: İ.Ü Orman Fakültesi Yayınları, 1971, ss. 75-110.

[6] H. Spiecker, "Growth of Norway Spruce (Picea abies (L.) Karst.) under changing environmental conditions in Europe," Spruce Monocultures in Central Europe: Problems and Prospects Conf., 2000, pp. 11-26.

[7] T. Odabaşı, A. Çalışkan, ve H. F. Bozkuş, Orman Bakımı, İstanbul, Türkiye: İ.Ü. Orman Fakültesi Yayınları, 2004.

[8] E. Çiçek, M. Yılmaz, F. Yılmaz, ve A. Usta, "Aralamanın dar yapraklı dişbudak (Fraxinus angustifolia Vahl.) plantasyonlarında büyüme ve bazı toprak özelliklerine etkisi," TÜBİTAK Projesi Sonuç Raporu, Ankara, Türkiye, 2010.

[9] L. D. Dimov, E. Stelzer, K. Wharton, J. S. Meadows, J. L. Chambers and K. Ribbeck, "Effects of thinning intensity and crown class on cherrybark oak epicormic branching five years after treatments," Proc of the 13th Bien Southern Silvicultural Res Conference. USDA Forest Service, 2006, pp. 606-610.

[10] J. S. Meadows, "Logging Damage to Residual Trees Following Partial Cutting in an Green Ash-Sugarberry Stand in the Mississippi Delta," United States Department Of Agriculture Forest Service General Technical Report Nc, pp. 248-260, 1993.

[11] J. S. Meadows and J. D. Hodges, "Silviculture of southern bottomland hardwoods: 25 years of change," 25th Annual Hardwood Symp., 1997, pp. 1-16.

[12] J. S. Meadows, "Epicormic branches and lumber grade of bottomland oak," Proc of the 23rd Ann Harwood Symp., 1995, pp. 19-25.

[13] S. G. Pallardy, Physiology of woody plants, $3^{\text {rd }}$ ed., California, USA: Elsevier, 2010.

[14] P. H. Davis, J. Cullen, and M. J. E. Coode, Flora of Turkey and the east Aegean islands, Vol. 7, Edinburgh, United Kingdom: Edinburgh University Press, 1988, pp. 659-683.

[15] F. Yaltirik, Türkiye meşeleri teşhis kılavuzu (The oak trees of Turkey), Istanbul, Türkiye: Yenilik Basimevi, 1984.

[16] Orman Genel Müdürlüğ̈̈, Türkiye orman varlı̆ğ, Ankara, OGM Orman İdaresi ve Planlama Dairesi Başkanlığ Yayınları, 2012. 
[17] M. Genç, Silvikültür tekniği. Isparta, Türkiye: S.D.Ü. Orman Fakültesi Yayınları, 2013.

[18] Anonim, (28 Mayıs 2018) Düzce meteoroloji istasyonu iklim verileri (1962-2017), Ankara, Meteoroloji Genel Müdürlüğü, Erişim: https://www.mgm.gov.tr/veridegerlendirme/il-ve-ilceleristatistik.aspx $? \mathrm{k}=\mathrm{A} \& \mathrm{~m}=\mathrm{DUZCE}$.

[19] H. Spiecker, "Zur Steuerung des Dickenwachstums und der Astreinigung von Trauben-und Stieleichen (Quercus petraea (Matt.) Liebl. und Quercus robur L.)," Schriftenreihe der Landesforstverwaltung, vol. 72, p. 150, 1991.

[20] F. Colin, N. Robert, J.-L. Druelle and F. Fontaine, "Initial spacing has little influence on transient epicormic shoots in a 20-year-old sessile oak plantation," Annals of forest science, vol. 65, p. 508, 2008.

[21] S. Yokoi and K. Yamaguchi, "Origin of epicormic branches and effect of thinning on their development in Quercus mongolica var. grosseserrata," Journal of the Japanese Forestry Society, vol. 78, pp. 169-174, 1996.

[22] J. S. Meadows and J. Goelz, "Fourth year effects of thinning on growth and epicormic branching in a red oaksweetgum stand on a minor stream bottom site in West-Central Alabama," Proc of the 11th Bien Southern Silvicultural Res Conference (USDA Forest Service), Asheville, NC, USA, 2002, pp. 201-208.

[23] T. A. Wignall, G. Browning and K. A. D. Mackenzie, "The physiology of epicormic bud emergence in pedunculate Oak ( Quercus robur L.) responses to partial notch girdling in thinned and unthinned stands," Forestry: An International Journal of Forest Research, vol. 60, pp. 45-56, 1987.

[24] D. E. Hibbs, W. H. Emmingham and M. C. Bondi, "Thinning red alder: effects of method and spacing," Forest Science, vol. 35, pp. 16-29, 1989.

[25] E. Çiçek, F. Yılmaz, A. K. Özbayram ve T. Çitgez, "Aralama Şiddeti ve Gövde Sınıfının Dar Yapraklı Dişbudakta (Fraxinus angustifolia Vahl.) Su Sürgünü Oluşumuna Etkisi," Artvin Çoruh Üniversitesi Orman Fakültesi Dergisi, c. 13, s.1, ss. 40-48, 2012.

[26] W. K. Clatterbuck, "Growth of a 30-year cherrybark oak plantation 6 years after thinning," 11th Bien Southern Silvicultural Res Conf., 2002, pp. 201-208.

[27] W. Clatterbuck, "Are overtopped white oak good candidates for management," U.S. Department of Agriculture-Proceedings at the seventh biennial Southern silvicultural research conf., 1993, pp.497-500.

[28] F. Colin, R. Mechergui, J.-F. Dhôte and F. Fontaine, "Epicormic ontogeny on Quercus petraea trunks and thinning effects quantified with the epicormic composition," Annals of Forest Science, vol. 67, pp. 813-813, 2010. 